\title{
Development and characterization of 21 microsatellite markers in Daphne kiusiana, an evergreen broad-leaved shrub endemic to Korea and Japan
}

\author{
Jung-Hyun Lee, Won-Bum Cho' ${ }^{1}$, Sungyu Yang², Eun-Kyeong Han, Eun-Seo Lyu, Wook Jin \\ $\mathrm{Kim}^{2}$, Byeong Cheol Moon ${ }^{2}$ and Goya Choi ${ }^{2 *}$ \\ Department of Biology Education, Chonnam National University, Gwangju 61186, Korea \\ ${ }^{1}$ Department of Biological Sciences, Inha University, Incheon 22212, Korea \\ ${ }^{2} K$-herb Research Center, Korea Institute of Oriental Medicine, Daejeon 34054, Korea \\ (Received 31 January 2017; Revised 18 February 2017; Accepted 27 February 2017)
}

\begin{abstract}
Microsatellite markers were isolated for Daphne kiusiana var. kiusiana (Thymelaeaceae), an evergreen broad-leaved shrub endemic to Korea and Japan. Because its populations in Jeju Island are morphologically controversial, and consistently threatened by anthropogenic pressures, taxonomic delimitation and conservation effort are required at the genetic level. We developed 21 polymorphic microsatellite loci from Next Generation Sequencing data. The primer set included di-, tri-, and tetra-nucleotide repeats. Variability in the markers was tested for 80 individuals of D. kiusiana from three natural populations in Jeju Island and Japan. Among the 21 loci, three were unavailable for population JKJU of Japan. The Neighbor-Joining tree based on microsatellite markers described here classified the three populations into two groups according to geographical or morphological traits. These will be a powerful genetics tool for determining the taxonomic boundary and establishing suitable conservation strategies for D. kiusiana in Jeju Island.
\end{abstract}

Keywords: conservation, Daphne kiusiana, Jeju Island, microsatellite markers, taxonomic entity

Approximately 2,000 islands are found in a narrow band along the southern coastal region of Korean Peninsula including Jeju Island (Yang, 2013). This edge zone is disjunctively located on the northwestern margin of an equivalent climatic area of Japan, and is covered by various evergreen broad-leaved tree species (Satake et al., 1989; Lee and Choi, 2010). Thus, Korean populations of a given species may have an important evolutionary property (J.-H. Lee et al., 2013; Lee et al., 2014) that has guaranteed their long-term survival in East Asia (Frankham, 2005; Ouborg et al., 2006; Willi et al., 2006).

Daphne kiusiana Miq. var. kiusiana is an evergreen broadleaved shrub endemic to Korea (mostly on Jeju Island) and Japan. However, plants on Jeju Island are sometimes regarded as a different species with D. kiusiana in Japan because of several unique morphological traits, e.g., a glabrous calyx and lobes, and elliptical leaves (c.f., D. jejudoensis M. Kim) (J.
Lee et al., 2013). Therefore, a clearer boundary of taxonomic delimitation is needed. Moreover, natural populations in Korea are threatened by anthropogenic pressures, i.e., disturbances that have caused habitat destruction due to urbanization as well as over-collecting of specimens for commercial purposes (Ro et al., 2010). For example, because of its graceful shape (resembling a bride's bouquet) and pleasant fragrance, it is commonly used as an ornamental (Ro et al., 2010). Populations there are now extremely restricted to several islands, including Geoje and Jeju, where plants are being managed as endangered organisms (Korea National Arboretum, 2008). Despite these protective measures, human activity continues to threaten their existence. Therefore, we developed a set of polymorphic microsatellite markers from $D$. kiusiana to resolve this debate about the taxonomic entity of Jeju populations and establish a suitable conservation strategy for Korean populations based on genetic diversity and structure.

\footnotetext{
*Author for correspondence: serparas@kiom.re.kr
} 


\section{Materials and Methods}

To acquire our microsatellite library, we used a DNeasy Plant Mini Kit (Qiagen, Seoul, Korea) to extract genomic DNA from a fresh leaf of a single plant sampled at Sinpyeonggotjawal, Jeju Island, Korea (Table 1). Measurements were made with a NanoDrop ND-1000 (NanoDrop Technologies, Wilmington, DE, USA). Applying a Next Generation Sequencing (NGS) approach, we sequenced high-quality DNA (concentration: $46 \mathrm{ng} / \mu \mathrm{L}$; A260/280 $=1.73 ; \mathrm{A} 260 / 230=1.64$ ) using the Illumina MiSeq platform (LAS, Seoul, Korea). In all, 4,936,656 reads $(2 \times$ $300 \mathrm{bp}$ ) were produced by Illumina paired-end sequencing and then trimmed by Trimmomatic 0.32 (Bolger et al., 2014).

To identify the microsatellites from those reads, we screened them with SSR pipeline v. 0.951 (Miller et al., 2013). The parameters were set for detection of di-, tri-, or tetra-nucleotide motifs with flanking regions larger than $50 \mathrm{bp}$ and having at least 10,6 , or 4 repeats, respectively. From this screening, we acquired 28,495 sequences that were then re-filtered in an attempt to reference-map all of the reads to each microsatellite that contained a singleton. This was accomplished with Geneious R7.1.8 (Biomatters; available from http://www.geneious.com). After discarding putative multi-copy loci with exceptionally high coverage, we selected fragments with unique patterns that had two separate alleles, few variations at the site to which a primer was attached, and no additional single nucleotide polymorphisms in the flanking region. Finally, we designed 140 primer pairs with Primer3 in Geneious R7, and synthesized with a taq sequence (5'-CACGACGTTGTAA AACGAC-3') to enable incorporation with M13 primer labeled at the 5'-end with a 6-FAM fluorescent dye.

To test the effectiveness of the developed microsatellite loci, we collected 80 individuals of D. kiusiana from three natural populations in Korea and Japan (Table 1). To minimize the damage to this study species, only one plant per population was taken to prepare a voucher specimen that was then deposited in the herbarium at the Korea Institute of Oriental Medicine (KIOM). The DNA was extracted as described above, and PCR was conducted with a GeneAmp ${ }^{\circledR}$ PCR System 2700 Thermal Cycler (Applied Biosystems, Foster City, CA, USA), using a final volume of $10 \mu \mathrm{L}$ that comprised 15 to $20 \mathrm{ng}$ of extracted DNA, $5 \mu \mathrm{L}$ of $\mathrm{Solg}^{\mathrm{TM}}$ $2 \times$ Taq PCR Smart-Mix I (Solgent, Daejeon, Korea), $0.01 \mu \mathrm{M}$ forward primer, $0.2 \mu \mathrm{M}$ reverse primer, and $0.1 \mu \mathrm{M}$ of the M13 primer (fluorescently labeled). The PCR amplifications were performed under the following conditions: initial denaturation at $95{ }^{\circ} \mathrm{C}$ for $2 \mathrm{~min}$; then 30 cycles of denaturing at $94{ }^{\circ} \mathrm{C}$ for $30 \mathrm{~s}$, annealing at 53 to $58{ }^{\circ} \mathrm{C}$ for $45 \mathrm{~s}$, and extension at $72{ }^{\circ} \mathrm{C}$ for $45 \mathrm{~s}$; with a final extension at $72^{\circ} \mathrm{C}$ for $7 \mathrm{~min}$. Without dilution of fluorescently labeled PCR products, $1 \mu \mathrm{L}$ was analyzed concurrently with the GeneScan ${ }^{\mathrm{TM}}-500 \mathrm{LIZ}^{\mathrm{TM}}$ Size Standard (Applied Biosystems) on an ABI 3730XL sequencer (Applied Biosystems). Allele sizes were manually determined three times with GENEMAPPER 3.7 software (Applied Biosystems). The number of alleles plus values for $H_{\mathrm{E}} \quad$ (expected heterozygosity) and $H_{\mathrm{O}}$ (observed heterozygosity) were obtained with GenAlEx 6 (Peakall and Smouse, 2006). Deviations from Hardy-Weinberg equilibrium (HWE) was estimated with GENEPOP 4.0 (Rousset, 2008).

To determine the genetic association among the three populations, we quantified their relationship using a proportion of shared alleles $\left(D_{\mathrm{ps}}\right)$ based on 19 loci. Only DKi134 and DKi140 were excluded. The pair-wise genetic distance $\left(D_{\mathrm{ps}}\right)$ was generated with MSA software (Dieringer and Schlöterer, 2003) using a bootstrap analysis of 1,000 replicates. From these distance matrices, we constructed $50 \%$ consensus trees by the Neighbor-Joining (NJ) method, as implemented in PHYLIP ver. 3.68 (Felsenstein, 2004).

\section{Results and Discussion}

Of the developed 140 primer pairs, 21 proved to be polymorphic while the rest either were insufficiently amplified

Table 1. Voucher and location information for Daphne kiusiana samples used in this study. One specimen per population was deposited in the herbarium at the Korea Institute of Oriental Medicine (KIOM).

\begin{tabular}{|c|c|c|c|}
\hline Voucher no. & Locality & Geographic coordinates & No. of individuals \\
\hline LJH_KIOM-2015-4 & Sinpyeonggotjawal, Jeju Island, Korea (KJSI) & $33^{\circ} 16^{\prime} \mathrm{N}, 126^{\circ} 15^{\prime} \mathrm{E}$ & 1 \\
\hline LJH_KIOM-2015-5 & Cheongsugotjawal, Jeju Island, Korea (KJCH) & $33^{\circ} 18^{\prime} \mathrm{N}, 126^{\circ} 16^{\prime} \mathrm{E}$ & 30 \\
\hline YSG_KIOM-2016-40 & Seonheulgotjawal, Jeju Island, Korea (KJSE) & $33^{\circ} 31^{\prime} \mathrm{N}, 126^{\circ} 42^{\prime} \mathrm{E}$ & 28 \\
\hline LJH_KIOM-2015-58 & Juboyama, Kyushu, Japan (JKJU) & $33^{\circ} 28^{\prime} \mathrm{N}, 130^{\circ} 04^{\prime} \mathrm{E}$ & 22 \\
\hline
\end{tabular}


Table 2. Characteristics of 21 microsatellite loci developed in Daphne kiusiana.

\begin{tabular}{|c|c|c|c|c|c|c|}
\hline Locus & Primer sequence $\left(5^{\prime}-3^{\prime}\right)^{\mathrm{a}}$ & $\begin{array}{c}\text { Repeat } \\
\text { motif }\end{array}$ & $A$ & $T_{\mathrm{m}}\left({ }^{\circ} \mathrm{C}\right)$ & $\begin{array}{c}\text { Size } \\
\text { range }(\mathrm{bp})\end{array}$ & $\begin{array}{c}\text { GenBank } \\
\text { accession No. }\end{array}$ \\
\hline DKi019 & $\begin{array}{l}\text { F: CCTAATGATTTAGACCGCT } \\
\text { R: TTCTGGTGAGAAACGAAC }\end{array}$ & $(\mathrm{CT})_{12}$ & 5 & 53 & $206-232$ & KT932539 \\
\hline DKi020 & $\begin{array}{l}\text { F: GTACAGATCTCAATTGGTCT } \\
\text { R: GATAGCAATCATCCATCAAG }\end{array}$ & $(\mathrm{CT})_{13}$ & 4 & 53 & $244-252$ & KT932540 \\
\hline DKi021 & $\begin{array}{l}\text { F: CGTTTAGGGTGTAAGTCATA } \\
\text { R: TACTCGATCCATCCCTATTA }\end{array}$ & $(\mathrm{CT})_{16}$ & 7 & 53 & $267-285$ & KT932541 \\
\hline DKi022 & $\begin{array}{l}\text { F: CAGAGACAGGATTGAACAT } \\
\text { R: ATTGGATACGTGTTAGGTC }\end{array}$ & $(\mathrm{GA})_{13}$ & 6 & 53 & $197-215$ & KT932542 \\
\hline DKi023 & $\begin{array}{l}\text { F: CAGTTGAGGATGTCATATCA } \\
\text { R: GCCGAATGTGTTATTTGTC }\end{array}$ & $(\mathrm{GA})_{13}$ & 6 & 53 & $279-293$ & KT932543 \\
\hline DKi101 & $\begin{array}{l}\text { F: AGATGCTGGTTCATGTTCG } \\
\text { R: GGAACACAGTTGAACGTTG }\end{array}$ & $(\mathrm{AC})_{10}$ & 5 & 53 & $179-193$ & KT932572 \\
\hline DKi104 & $\begin{array}{l}\text { F: CCTGCGATCTGGGTAATTT } \\
\text { R: AGGCCACACAACAAGAATC }\end{array}$ & $(\mathrm{AT})_{10}$ & 4 & 58 & $239-251$ & KT932574 \\
\hline DKi062 & $\begin{array}{l}\text { F: ATCAACAATCTACTCCTGC } \\
\text { R: CACTCCTTCCAGAACTAAG }\end{array}$ & $(\mathrm{ATG})_{8}$ & 4 & 53 & $247-262$ & KT932553 \\
\hline DKi070 & $\begin{array}{l}\text { F: AGAAGATGATGCCAAGATG } \\
\text { R: GGAAGACTTAACGGCTAAT }\end{array}$ & $(\mathrm{GAA})_{9}$ & 4 & 58 & $245-254$ & KT932557 \\
\hline DKi072 & $\begin{array}{l}\text { F: AAGGTGGGAGATTCTGATA } \\
\text { R: GAGCACTAGACAATTCCTT }\end{array}$ & $(\mathrm{GAT})_{8}$ & 2 & 53 & 199-205 & KT932558 \\
\hline DKi073 & $\begin{array}{l}\text { F: GTCTTAGGGCTAGTGATTC } \\
\text { R: GACCGTCAAGTCTTCTATT }\end{array}$ & $(\mathrm{GAT})_{9}$ & 3 & 53 & $248-263$ & КT932559 \\
\hline DKi082 & $\begin{array}{l}\text { F: TCAAGACCAATATTGCCAG } \\
\text { R: CTCCATGAGGTGATTCATT }\end{array}$ & $(\mathrm{TGA})_{8}$ & 4 & 53 & $183-201$ & KT932564 \\
\hline DKi117 & $\begin{array}{l}\text { F: ATAGTTCTTGTGCCACCAC } \\
\text { R: TAGCCAAGTCGTTGTCTTG }\end{array}$ & $(\mathrm{ATA})_{6}$ & 2 & 53 & $263-266$ & КT932579 \\
\hline DKi119 & $\begin{array}{l}\text { F: AAGCACAATCATGGAGCAT } \\
\text { R: ATCGTCAGAACTAGCCTGA }\end{array}$ & $(\mathrm{CTT})_{6}$ & 7 & 53 & $172-208$ & KT932580 \\
\hline DKi091 & $\begin{array}{l}\text { F: TGAGAGACTCAGTACTCTC } \\
\text { R: ACTACCACTCTCTGTTTCT }\end{array}$ & $(\mathrm{AGAA})_{5}$ & 3 & 53 & $309-317$ & КT932569 \\
\hline DKi097 & $\begin{array}{l}\text { F: ACTTGTCCTCAACTTTCTC } \\
\text { R: TATTTGATGATCAGGTCGC }\end{array}$ & $(\text { TTAA })_{5}$ & 3 & 53 & $242-258$ & KT932571 \\
\hline DKi128 & $\begin{array}{l}\text { F: ATAAAGCGGAATGGAGTCG } \\
\text { R: ACAGTAGTAGGTCCCACAC }\end{array}$ & $(\mathrm{TTGA})_{7}$ & 3 & 53 & $179-187$ & КT932585 \\
\hline DKi129 & $\begin{array}{l}\text { F: AGTTCAGACGCTTCAACC } \\
\text { R: CCATCCACAGAGACAGATTC }\end{array}$ & $(\mathrm{CATA})_{6}$ & 4 & 58 & $296-312$ & КT932586 \\
\hline DKi131 & $\begin{array}{l}\text { F: GAAACTCGTCTCTCTTCCTC } \\
\text { R: GACGACTACCATAGCATAGC }\end{array}$ & $(\text { AGGA })_{5}$ & 2 & 53 & 199-203 & KT932588 \\
\hline DKi134 & $\begin{array}{l}\text { F: AGTGCTTTAATGGAAGGCT } \\
\text { R: GATCACCTCCTAACCAAGC }\end{array}$ & $(\mathrm{CTAT})_{4}$ & 2 & 58 & $203-223$ & КТ932589 \\
\hline DKi140 & $\begin{array}{l}\text { F: ATTCACACCCTAGTCGGAT } \\
\text { R: GAAACAAAGCTGAGCGAAG }\end{array}$ & $(\text { TGTA })_{4}$ & 2 & 53 & $215-219$ & КТ932590 \\
\hline
\end{tabular}

$A$, number of alleles; $T_{\mathrm{m}}$, PCR annealing temperature.

${ }^{\text {a}}$ All forward primers were M13 (5'-CACGACGTTGTAAAACGAC-3')-tailed at the 5'-end. 
Table 3. Genetic parameters of 21 microsatellite loci for separate populations of Daphne kiusiana sampled in Jeju Island (KJCH and KJSE) and Japan (JKJU).

\begin{tabular}{|c|c|c|c|c|c|c|c|c|c|c|c|c|}
\hline \multirow{2}{*}{ Locus } & \multicolumn{4}{|c|}{$\mathrm{KJCH}^{\mathrm{a}}(n=30)$} & \multicolumn{4}{|c|}{$\operatorname{KJSE}^{\mathrm{a}}(n=28)$} & \multicolumn{4}{|c|}{ 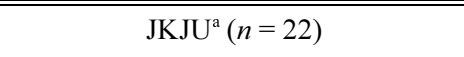 } \\
\hline & $A$ & $H_{\mathrm{E}}$ & $H_{\mathrm{O}}$ & $S r$ & $A$ & $H_{\mathrm{E}}$ & $H_{\mathrm{O}}$ & $S r$ & $A$ & $H_{\mathrm{E}}$ & $H_{\mathrm{O}}$ & $S r$ \\
\hline DKi019 & 2 & 0.500 & 0.467 & $216-218$ & 2 & 0.436 & 0.429 & $216-218$ & 3 & 0.458 & $0.136^{*}$ & $206-232$ \\
\hline DKi020 & 2 & 0.095 & 0.100 & $244-248$ & 2 & 0.035 & 0.036 & $248-250$ & 3 & 0.241 & 0.273 & $248-252$ \\
\hline DKi021 & 5 & 0.537 & 0.600 & $275-285$ & 4 & 0.198 & $0.143^{*}$ & $275-285$ & 2 & 0.434 & $0.000^{*}$ & $267-269$ \\
\hline DKi022 & 3 & 0.493 & 0.467 & $197-213$ & 3 & 0.601 & $0.643^{*}$ & $197-201$ & 2 & 0.351 & $0.091 *$ & $211-215$ \\
\hline DKi023 & 3 & 0.443 & 0.300 & $287-293$ & 2 & 0.459 & 0.571 & $287-291$ & 3 & 0.507 & $0.091^{*}$ & $279-283$ \\
\hline DKi101 & 3 & 0.259 & $0.200 *$ & $179-183$ & 2 & 0.163 & 0.107 & $179-181$ & 2 & 0.351 & $0.091^{*}$ & 189-193 \\
\hline DKi104 & 3 & 0.509 & 0.433 & $245-251$ & 2 & 0.226 & 0.185 & $245-249$ & 1 & 0.000 & 0.000 & 239 \\
\hline DKi062 & 2 & 0.498 & 0.467 & $259-262$ & 2 & 0.219 & 0.250 & $259-262$ & 2 & 0.044 & 0.045 & $247-256$ \\
\hline DKi070 & 3 & 0.513 & 0.700 & $245-254$ & 2 & 0.494 & 0.464 & $245-251$ & 1 & 0.000 & 0.000 & 248 \\
\hline DKi072 & 2 & 0.444 & 0.467 & 199-205 & 2 & 0.293 & 0.286 & 199-205 & 1 & 0.000 & 0.000 & 205 \\
\hline DKi073 & 3 & 0.496 & $0.433 *$ & $248-263$ & 2 & 0.436 & 0.357 & $248-254$ & 1 & 0.000 & 0.000 & 248 \\
\hline DKi082 & 2 & 0.064 & 0.067 & $195-198$ & 3 & 0.070 & 0.071 & 195-201 & 1 & 0.000 & 0.000 & 183 \\
\hline DKi117 & 2 & 0.339 & 0.233 & $263-266$ & 2 & 0.484 & 0.464 & $263-266$ & 1 & 0.000 & 0.000 & 263 \\
\hline DKi119 & 4 & 0.585 & 0.567 & $172-208$ & 4 & 0.284 & 0.321 & $178-208$ & 3 & 0.433 & 0.545 & 193-199 \\
\hline DKi091 & 2 & 0.406 & 0.433 & $313-317$ & 2 & 0.357 & 0.393 & $313-317$ & 1 & 0.000 & 0.000 & 309 \\
\hline DKi097 & 2 & 0.278 & $0.133^{*}$ & $242-250$ & 2 & 0.316 & 0.250 & $242-250$ & 1 & 0.000 & 0.000 & 258 \\
\hline DKi128 & 3 & 0.415 & 0.367 & $179-187$ & 2 & 0.497 & 0.357 & $183-187$ & 2 & 0.044 & 0.045 & $179-183$ \\
\hline DKi129 & 2 & 0.206 & 0.233 & $308-312$ & 1 & 0.000 & 0.000 & 308 & 2 & 0.397 & 0.545 & 296-304 \\
\hline DKi131 & 2 & 0.480 & $0.267 *$ & 199-203 & 2 & 0.499 & 0.464 & 199-203 & 1 & 0.000 & 0.000 & 203 \\
\hline DKi134 & 2 & 0.444 & 0.333 & $203-223$ & 2 & 0.494 & 0.607 & $203-223$ & 0 & $N / A$ & $N / A$ & $N / A$ \\
\hline DKi140 & 2 & 0.095 & 0.100 & $215-219$ & 1 & 0.000 & 0.000 & 219 & 0 & $N / A$ & $N / A$ & $N / A$ \\
\hline
\end{tabular}

$A$, number of alleles; $H_{\mathrm{E}}$, expected heterozygosity; $H_{\mathrm{O}}$, observed heterozygosity; $\mathrm{Sr}$, size range; $N / A$, unavailable PCR products.

*Significant deviations from Hardy-Weinberg equilibrium $(P<0.05)$.

${ }^{\text {a }}$ Population symbols are the same as those used in parentheses for Table 1.

or else produced inconsequential peaks (Table 2). Overall, the alleles numbered 2 to 7 (average of 3.90). Values for $H_{\mathrm{E}}$ and $H_{\mathrm{O}}$ ranged from 0.000 to 0.601 and from 0.000 to 0.700 , respectively (Table 3). Among the 21 loci, two and nine were monomorphic in Jeju population KJSE and Japanese population JKJU, respectively. Loci DKi134 and DKi140 were not amplified in the Japanese population. Furthermore, nine polymorphic and monomorphic loci clearly did not overlap between Jeju Island and Japan within the size range of those alleles (Table 3). Although eight loci showed significant deviations from Hardy-Weinberg equilibrium, this was not consistent across populations. The NJ tree classified the three populations into two groups according to geographical or morphological traits (Jeju Island vs. Japan) with a remarkably high bootstrap value of 100 (Fig. 1). The microsatellite markers described here will be a powerful genetics tool for elucidating the taxonomic entity of Jeju populations, and in the organization of conservation programs planned to reduce inbreeding via artificial crossbreeding and to minimize loss of genetic variability in Jeju populations. Also, we expect that

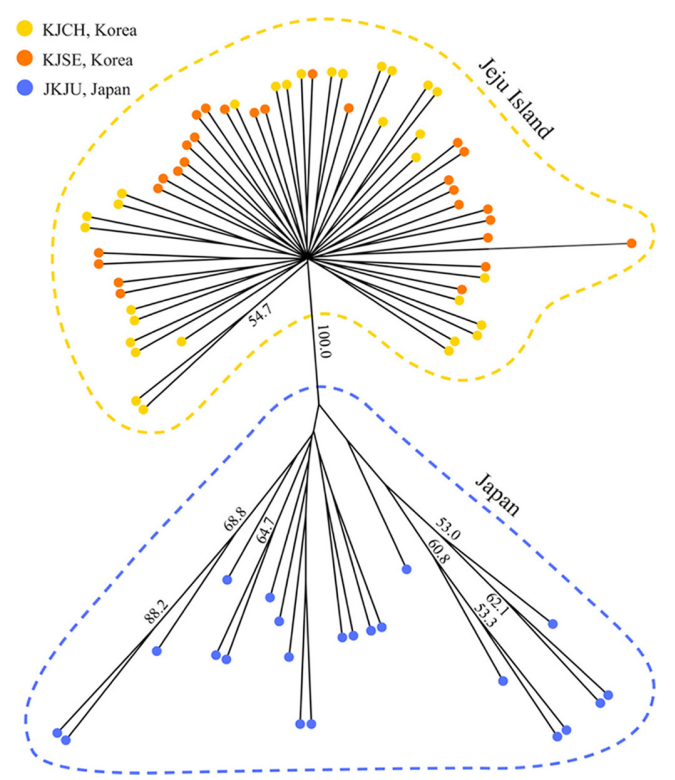

Fig. 1. Neighbor-Joining tree for 3 populations of D. kiusiana in Jeju Island and Japan based on proportion of shared alleles $\left(D_{\mathrm{ps}}\right)$. Colored circles on branch tips indicate number of individuals for each population. Bootstrap support at internodes is shown if value is $>50 \%$. 
they will also improve our understanding about historical and contemporary gene flow, not only on a fine scale within Korea but also on a larger scale across the entire range of this species.

\section{Acknowledgments}

The authors thank two colleagues Choi IS and Jin DP at the Plant Systematics Laboratory of Inha University for help in assisting with statistical analysis. This work was supported by the National Research Foundation of Korea (NRF) (No. NRF2016R1C1B2012150), and a basic grant (K16401) for the Kherb Research Center, Korea Institute of Oriental Medicine.

\section{Literature Cited}

Bolger, A. M., M. Lohse and B. Usadel. 2014. Trimmomatic: A flexible trimmer for Illumina sequence data. Bioinformatics 30: 2114-2120.

Dieringer, D. and C. Schlötterer. 2003. Microsatellite Analyser (MSA): A platform independent analysis tool for large microsatellite data sets. Molecular Ecology Notes 3: 167-169.

Felsenstein, J. 2004. PHYLIP: Phylogeny inference package. Department of Genome Sciences and Department of Biology, University of Washington, Seattle, WA.

Frankham, R. 2005. Genetics and Extinction. Biological Conservation 126: 131-140.

Korea National Arboretum. 2008. Rare Plants Data Book in Korea. Korea National Arboretum, Pocheon, 332 pp. (in Korean)

Lee, J.-H. and B.-H. Choi. 2010. Distribution and northernmost limit on the Korean Peninsula of three evergreen trees. Korean Journal of Plant Taxonomy 40: 267-273.

Lee, J.-H., D.-H. Lee and B.-H. Choi. 2013. Phylogeography and genetic diversity of East Asian Neolitsea sericea (Lauraceae) based on variations in chloroplast DNA sequences. Journal of
Plant Research 126: 193-202.

Lee, J.-H., D.-H. Lee, I.-S. Choi and B.-H. Choi. 2014. Genetic diversity and historical migration patterns of an endemic evergreen oak, Quercus acuta, across Korea and Japan, inferred from nuclear microsatellites. Plant Systematics and Evolution 300: 1913-1923.

Lee, J., K.-H. Lee, S. So, C. Choi and M. Kim. 2013. A new species of Daphne (Thymelaeaceae): D. jejudoensis M. Kim. Korean Journal of Plant Taxonomy 43: 94-98.

Miller, M. P., B. J. Knaus, T. D. Mullins and S. M. Haig. 2013. SSR pipeline: A bioinformatics infrastructure for identifying microsatellites from paired-end Illumina high-throughput DNA sequencing data. Journal of Heredity 104: 881-885.

Ouborg, N. J., P. Vergeer and C. Mix. 2006. The rough edges of the conservation genetics paradigm for plants. Journal of Ecology 94: 1233-1248.

Peakall, R. and P. E. Smouse. 2006. GenAlEx 6: Genetic Analysis in Excel. Population genetic software for teaching and research. Molecular Ecology Notes 6: 288-295.

Rousset, F. 2008. GENEPOP'007: A complete reimplementation of the genepop software for Windows and Linux. Molecular Ecology Resources 8: 103-106.

Ro, N. Y., E. Y. Song, S. C. Kim, H. C. Ko and S. Y. Lee. 2010. Propagation of a rare variety Daphne kiusiana Miq. in Korea through softwood cuttings. Journal of Bio-Environment Control 19: 246-250. (in Korean)

Satake, Y., H. Hara, S. Watari and T. Tominari. 1989. Wild Flowers of Japan: Woody Plants. Heibonsha, Tokyo, 300 pp.

Willi, Y., J. Van Buskirk and A. A. Hoffmann. 2006. Limits to the adaptive potential of small populations. Annual Review of Ecology, Evolution, and Systematics 37: 433-458.

Yang, S. J. 2013. The distribution analysis for the flora of uninhabited islands in the Gyeongsangnamdo. MS thesis, Changwon National University, Changwon, Korea, 87 pp. (in Korean) 